\title{
Part 14. Negligence versus Malpractice: The "Reasonable Man Rule"
}

SADJ October 2017, Vol 72 no 9 p430 - p432

LM Sykes ${ }^{1}$, WG Evans ${ }^{2}$, HD Dullabh ${ }^{3}$

\section{INTRODUCTION}

Negligence refers to the breach of a duty of care which results in damage. It occurs when a person's conduct falls below the standards of behaviour established by law for the protection of others against unreasonable risk of harm. A person has acted negligently if he or she has departed from the conduct expected of a reasonably prudent person acting under similar circumstances. In a legal situation, in order to establish negligence it must be proven that the defendant had a duty to the claimant, the defendant breached that duty by failing to conform to the required standard of conduct, the defendant's negligent conduct was the cause of the harm incurred by the claimant, and the latter was, in fact, harmed or damaged. ${ }^{1}$

\section{LITERATURE REVIEW}

\section{Negligence}

Historically, English Common Law imposed liability for all wrongful acts. However, the concept of negligence only emerged as an independent entity in the eighteenth century, when the concept of legal liability for a "failure to act" emerged. This was originally imposed on those who undertook to perform a service, but failed to exercise care or skill in carrying out that service. This breach of promise to exercise care, whether overt or implied, formed the origins of the concept of "duty". 1 These ideas spread and today negligence is one of the most wide-ranging misdemeanors, encompassing most forms of unintentional or wrongful conduct where others are injured. While the actual laws pertaining to negligence may differ throughout the world, the basic notions and values remain the same. One of the most important arguments used in negligence law is that of the "reasonable person," which provides the standard by which their conduct is judged. ${ }^{1}$

1. Leanne M Sykes: BSc, BDS, MDent (Pros), Dip Res Ethics (Irensa), Dip Forensic Odont. Department of Prosthodontics, University of Pretoria.

2. William G Evans: BDS, Dip Orth. Department of Orthodontics, University of Witwatersrand.

3. Hermant D Dullabh: BChD, MSc (Dent), MDent (Pros), Department of Prosthodontics, University of Pretoria

Corresponding author

Leanne M Sykes:

Department of Prosthodontics, University of Pretoria.

E-mail: leanne.sykes@up.ac.za

\subsection{The "Reasonable Man Rule"}

By definition, "a person has acted negligently if they have departed from the conduct expected of a reasonably prudent person acting under similar circumstances. The hypothetical reasonable person provides an objective by which the conduct of others is judged". This helps distinguish negligence from intentional wrongdoing such as assault and battery where the actions were deliberate and intended to cause harm. A negligence suit, however, seeks to establish that failure of the defendant to act as a reasonable person caused the plaintiff's injury. It considers many factors including the person's knowledge, experience, and perceptions, the activity they are engaging in, and the circumstances surrounding their actions. ${ }^{1}$

In the medical / dental context, when a clinician engages in an activity requiring special skills, education, training, or experience, the standard by which their conduct is measured is the conduct of a reasonably skilled, competent, and experienced person who is a qualified member of the group authorized to engage in that activity. They cannot deny personal knowledge of basic aspects of the profession that are commonly known and practiced by their peers. The law does not make a special allowance for beginners with regard to special skills, and holds everyone to the standard of conduct of persons who are reasonably skilled and experienced in the activity.1 In addition, a person's physical characteristics or impairments and mental capacity does not excuse them from acting according to the reasonable person standard. Similarly, voluntary intoxication will not excuse conduct that is otherwise negligent. ${ }^{1}$

In the case of emergencies, the law recognizes that "even a reasonable person can make errors in judgment in such situations, and their conduct will be evaluated in light of whether it was a reasonable response under the circumstances, even though, in hindsight, another course of action might have avoided the injury". In other circumstances failure to anticipate the emergency could constitute negligence, as a reasonable person would have anticipated, and taken precautions against, the foreseeable emergency. ${ }^{1} \quad$ A further issue that is seldom considered is that a clinician could be held negligent by virtue of the patient's conduct. The law may consider that a trained professional should have taken into account the possible conduct of their patient, and regulated their own conduct accordingly. For example administering a double mandibular block to a child without anticipating that 
they would not understand the implications and damage they may inflict on themselves if they chewed while their mouths were still anaesthetized is negligent. Even adults given bilateral inferior alveolar nerve blocks experience loss of control of the tongue, collection of fluid in the oral cavity, weak bolus propulsion during swallowing and possible aspiration. ${ }^{2}$ A reasonable person must foresee the negligent conduct of others if the situation warrants.

\subsection{Proof of Negligence}

Proof of negligence is based on comparing the actions with those that a reasonable clinician, under the same circumstances, would have performed. To this end expert witnesses (colleagues) are often called upon to provide information beyond the common knowledge of the legal representatives, such as scientific evidence, interpretation of special investigations and test results, diagnosis, clinical procedures performed. They will also be asked to ascertain whether the accepted standard of care was given. To do this they may need to evaluate the conditions and circumstances, examine the patient if possible, and deliver a professional opinion. Note: it is easy to become emotional and accusatory when called upon to comment on the wrongdoings of others. However, one needs to remember that no third party can ever really know the full circumstances and details of what transpired during a clinical appointment. As such, findings should be presented in a clearly written document that reports on the current situation as observed clinically and radiographically. It should include a detailed description of the entire oral cavity, the tooth number, type of restorations present, and acceptability or problems associated with these, and may offer advice on possible solutions, including time and financial implications. Unless the expert witness has access to pre-operative records it will be impossible for he/she to report on the extent of damage caused by the accused colleague. As such the report should not include personal allegations accusations or assertions of guilt. Bear in mind that this document could be presented in a court of law, and all observations, opinions and deductions should be defensible and justifiable. Also consider that one never knows the exact circumstances, or issues that may have been beyond the clinician's control which could account for their actions.$^{1,3}$ Circumstantial evidence is very difficult to prove and when used in medical situations, the principle of Res Ipsa Loquitur (the thing speaks for itself) is invoked. Res ipsa loquitor argues that the injury could not have occurred in the absence of the clinician's negligence, was due to instrumentation or management that was exclusively under their control and that the injury would not have occurred if the clinician had acted with reasonable care. ${ }^{1}$

\subsection{Negligence and Duty}

Negligence on the grounds of duty refers to those situations where a pre-existing relationship creates an obligation to exercise care and to protect another person from harm. "While a person generally has a duty to not endanger the safety of others, they don't have a duty to render aid or prevent harm if it is from some other independent cause". A doctor who witnesses an accident has no duty to offer emergency medical assistance to the accident victims. However they can voluntarily decide to help, but are then obliged to exercise reasonable care in rendering that aid. This has resulted in doctors who have given medical assistance to accident victims being sued for negligence, and led to the so called "good Samaritan" rule to relieve them from negligence liability. ${ }^{1}$

\subsection{Patient Negligence}

There are times when the patient could have acted negligently and thus adding to their own injury. This is called "contributory negligence" and often results in their being unable to claim for the damages caused by the clinician. To compensate for this they may seek restitution based on "comparative negligence" in which their own negligence will not completely bar them from claiming damages, however their damages will be reduced by whatever percentage their own fault contributed to the injury. ${ }^{1}$ The clinician and patient may also have contradictory accounts as to the mechanism and extent of injury, based on their subjective recollection and interpretation of the events.

\subsection{Assumption of Risk}

This rule would allow a clinician to avoid liability for his/ her negligence by proving that the patient voluntarily consented to the procedure knowing its potential dangers and / or the dentist's limited capabilities. It is almost never used in a medical context. ${ }^{1}$

\section{Malpractice}

Reputation is a reflection of actions rather than words ${ }^{4}$

Malpractice is a legal term with a very specific definition. However in dentistry it can be defined as treatment provided by a dental care professional that is deemed to be below the acceptable standard of care expected from a dentist, that results in serious personal injuries to the patient. ${ }^{5}$ If a patient feels he/she have been injured by a dentist and wished to claim for malpractice there are four issues that need to be proven in the court of law: that the dentist was licensed, as this establishes that he/she had a duty to his/her patients to be professional and take care of them; that the dentist failed that duty through mistakes and poor treatment; that the mistake caused an injury; and that the injury resulted in damages. ${ }^{6}$ The damage may be physical harm such as scarring, injury to teeth or oral structures, or permanent loss of teeth, but could also include other costs such as lost time and wages, psychological trauma, incapacity, or extra medical or dental expenses. In a 12 year medico-legal survey of the most common dental malpractice claims in the USA, approximately one-quarter involved complications arising from extractions, including infections, sinus perforation and nerve damage. Twenty percent of claims resulted from endodontic procedures. Surgical errors included instruments left behind, air embolisms and nerve damage. Another quarter of the complaints involved injuries, fractures and infections resulting from implants, crowns and bridges. The rest of the cases included drug and anesthesia reactions, root resorption and other complications from orthodontics and braces, severe infections and failure to diagnose diseases. ${ }^{6}$ [This reference was purposefully inserted as an example to internet users to be wary and question information in web posts. In a follow up e-mail correspondence with the lawyer who published these results, it was established that the research had been conducted 20 years ago! Undoubtedly with the implant explosion, the figures would be different in 2017 than they were in the late nineties]. ${ }^{\text {? }}$

Disgruntled patients often present to a different practitioner when they feel they have been mistreated. 
This puts the second person in a difficult position of trying to establish whether the actions were negligent or severe enough to constitute malpractice? The authors propose using a three-pronged approach to evaluate the situation. This entails consideration of the: Magnitude, Frequency, and Intent.

To paraphrase Charles Babbage: The fatigue produced on human muscles does not only depend on the magnitude of the force employed in each effort, but also on the frequency with which it is exerted, ${ }^{8}$ and the individual's motivations (Leanne Sykes).

\subsection{Magnitude}

There is a common misconception that the magnitude scale is itself some kind of instrument or apparatus. Visitors will frequently ask to 'see the scale.' Charles Francis Richter. $^{9}$

This quotation with reference to earthquakes could quite easily also be applied to the difficulty one has determining the magnitude of a misdemeanor in the clinical context. A minor injury may be considered an adverse event in situations that were out of the clinician's hands, where a well justified decision turned out badly, where there may not be a universal agreement as to the best treatment option that should have been chose, or where the dentist displayed an isolated case of poor judgement or skills. These instances may be condoned if isolated, and are very often overlooked by the patients, whose memories fade as they heal or adapt. However more destructive damage that is detrimental to their oral health, function, appearance, psycho-social wellbeing, or puts their lives at risk could constitute negligence or malpractice. Very often the deciding factor between an adverse event, negligence and malpractice is determined by the magnitude.

Note: Informed consent is no protection against malpractice.

\subsection{Frequency}

Oscar Wilde said that "To err once is human, twice is careless."

In dentistry, an isolated adverse occurrence could be due to patient factors, the clinical situation, unavoidable damage or human error and negligence. However repeated injurious incidents, no matter how minor, may constitute carelessness at best and malpractice at worst. Arguably, if the latter is an isolated incident it should still only be considered negligent. However the practitioner should communicate with the patient immediately after the adverse event and offer to carry out all possible corrective measures or agree to some form of restitution.

\subsection{Intent}

"We judge others by their behaviour. We judge ourselves by our intentions" (lan Percy)..$^{10}$

Intention can be defined as: an act or instance of determining mentally upon some action or result; the end or object intended; purpose or attitude toward the effect of one's actions or conduct.

In legal terms (and alphabetically it seems) it refers to the aim, ambition, consilium, design, desire, destination, determination, direction, earnestness, end view, end intended, fixed direction, fixed purpose, goal, institutum, mark, object, objective, plan, propositum, purpose, resolution, resolve, set purpose, settled determination, target, ultimate purpose \{Burton, 2010 \#96\}. Any dental intervention carries with it a risk of error or failure. Complications can and do occur. It's impossible to save every tooth, to fully restore every mouth to optimal health or to satisfy every patient's oral needs. However, in determining negligence or malpractice, one would need to analyze the dentist's intention in terms of whether the action was beneficent or not. Questions to ask include: was the aim to provide a therapeutic benefit, to protect the patient, to prevent harm, to remove conditions that could lead to future harm, and was the therapy aimed at promoting the patient's best interests? ${ }^{11}$

\section{CONCLUSION}

In light of the above arguments, it is proposed that a transgression in any one of the three points be considered negligence, while liability in two or all three aspects could constitute malpractice. However all detected incidents of negligence should still be reported, documented and followed by a warning. Repeated offenses could signify a trend which would warrant Council investigation and intervention in order to protect future patients. At the same time, in order to protect clinicians against malpractice suites, there needs to be a stronger emphasis on teaching and practicing "evidence-based" rather than "experience-based" dentistry. To this end the dental profession need to collectively develop more extensive best practice guidelines.

\section{References}

1. Legal Dictionary L. The free dictionary - Negligence. Accessed on: 10-05-2017; Accessed at: http://legal-dictionary. thefreedictionary.com/Negligence

2. Jabbar J, Shekar V, Mitchell DA, Brennan PA. Should we be giving bilateral inferior alveolar and lingual nerve blocks for third molar surgery? Br J Oral Maxillofac Surg 2014;52(1):16-7.

3. Reasonable Man Theory Law \& Legal Definitions. definitions. uslegal.com/r/reasonable-man-theory. Accessed on: 01 05-2016;

4. Sonnenberg F. ACTIONS Speak Louder Than Words Personal Values. Accessed on: 15-05-2017; Accessed at: www.franksonnenbergonline.com/blog/actions-speaklouder-than-words

5. Dental Medical Malpractice. Dental Medical Malpractice Facts \& Claims Accessed on: 16-05-2017; Accessed at: www. malpracticecenter.com/dental-malpractice

6. Legalbeagle.com. What Constitutes Dental Malpractice? Accessed on: 16-05-2017; legalbeagle.com/5446060constitutes-dental-malpractice.html

7. Sykes LM, Harryparsad A, Evans W.G, Gani F. Social Media and Dentistry: Part 8: Ethical, legal, and professional concerns with the use of internet sites by health care professionals. SADJ. 2017;72(3):132-6.

8. Brainyquotes. Brainyquotes - Frequency. Accessed on: 12-05-2017; Accessed at:https://www.brainyquote.com/ quotes/quotes/c/charlesbab309736.html?src=t frequency

9. Brainyquotes. Brainyquotes - Magnitude Accessed on: 12-05-2017; Accessed at:https://www.brainyquote.com/ quotes/quotes/c/charlesbab309736.html?src=t_magnitude

10. Percy I. Think Exist .com. We judge others by their behavior. We judge ourselves by our intentions. Accessed on: 15-052017; Accessed at: thinkexist.com/quotation/we judge others_by_their_behavior-we

11. Naidoo S, Moodley, K. Ethics and the Dental Team. Schaik V, editor. Hatfield, Pretoria: Van Schaik; 2009. 136 p. 